\title{
A Decomposition Theorem on Euclidean Steiner Minimal Trees
}

\author{
F. K. Hwang, ' G. D. Song, ${ }^{2}$ G. Y. Ting, ${ }^{3}$ and D. Z. Du ${ }^{4}$ \\ ' AT\&T Bell Laboratories, Murray Hill, New Jersey, USA \\ ${ }^{2}$ Quiquihaer Light Engineering College, Heilungjiang, China \\ ${ }^{3}$ Quiquihaer Teacher's College, Heilungjiang, China \\ ${ }^{4}$ Mathematics Science Research Institute, Berkeley, California, USA
}

\begin{abstract}
The Euclidean Steiner minimal tree problem is known to be an NPcomplete problem and current alogorithms cannot solve problems with more than 30 points. Thus decomposition theorems can be very helpful in extending the boundary of workable problems. There have been only two known decomposition theorems in the literature. This paper provides a $50 \%$ increase in the reservoir of decomposition theorems.
\end{abstract}

\section{Introduction}

Let $F$ denote a given set of points on the Euclidean plane. A Steiner minimal tree (SMT) on $F$ is the shortest network (clearly, it has to be a tree) interconnecting $F$. Garey et al. [3] proved that the construction of SMTs for general sets of points is an NP-complete problem. Therefore, the ability to decompose an SMT problem into several smaller problems is of utmost importance and may very well determine whether a given problem is workable. Unfortunately, decomposition theorems are hard to come by for SMT problems. So far, there are only two decomposition theorems in existence.

Let $T$ be a tree interconnecting $F$ and let $X$ be a vertex of $T . X$ is called a fixed point if $X \in F$ and a Steiner point otherwise. The first decomposition theorem was proved by Gilbert and Pollak [4] as what they called the double wedge property. Suppose that two lines which cross at $120^{\circ}$ cut the plane into two $60^{\circ}$ wedges and two $120^{\circ}$ wedges. Let $R_{1}$ and $R_{2}$ denote the two closed $60^{\circ}$ wedges and let $X$ denote the point at which $R_{1}$ and $R_{2}$ meet. Let $F_{i}$ denote the set of fixed points in $R_{i}, i=1,2$. If $F_{1} \cup F_{2}=F$, then the SMT on $F$ is the union of the 


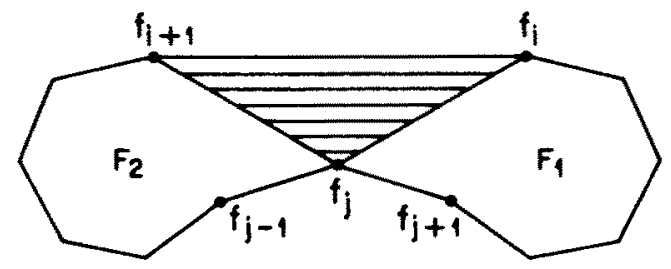

Fig. 1. Cockayne's decomposition.

SMT on $F_{1}$ and the SMT on $F_{2}$ plus a shortest edge to connect $F_{1}$ and $F_{2}$ (this edge is not necessary if $X \in F$ ).

We now present the second decomposition theorem due to Cockayne [1]. Gilbert and Pollak showed that the SMT on $F$ must lie within the convex hull of $F$. Let $P_{1}$ denote the convex polygon bounding the convex hull of $F$. Let $(p, q, r)$ be triple of fixed points satisfying:

(i) $p$ and $q$ are on $P_{1}, r$ is either on or within $P_{1}$,

(ii) $\Varangle$ prq $\geq 120^{\circ}$,

(iii) there are no other fixed points within the triangle pqr.

Let $P_{2}$ denote the polygon (called a Steiner polygon) obtained by deleting the triangle $p q r$ from $P_{1}$. We can now substitute $P_{2}$ for $P_{1}$ and proceed. When no more triples pqr can be found satisfying the conditions, we obtain a Steiner hull of $\boldsymbol{P}$ which contains all the points within the last Steiner polygon. Cockayne showed that the SMT on $F$ lies within the Steiner hull of $F$. Furthermore, suppose that for some $P_{i}$ the triple $(p, q, r)$ we find is such that $r$ is also on $P_{i}$. Let $f_{1}, f_{2}, \ldots, f_{m}, f_{1}$ denote the ordered sequence of fixed nodes on $P_{i}$ where $f_{i}=p$, $f_{i+1}=q, f_{j}=r$. Without loss of generality assume $i+1<j$. Let $F_{1}$ denote the set of fixed points bounded by the polygon $f_{1}, f_{2}, \ldots, f_{i}, f_{j}, f_{j+1}, \ldots, f_{m}, f_{1}$; and let $F_{2}$ denote the set of fixed points bounded by the Steiner polygon $f_{j}, f_{i+1}$, $f_{i+2}, \ldots, f_{j-1}, f_{j}$ (see Fig. 1). Then the SMT on $F$ is the union of the SMT on $F_{1}$ and the SMT on $F_{2}$.

The decomposition we are going to propose can be considered as an extension of Cockayne's result from deleting a triangle to deleting a quadrilateral (see Fig. 2).

In general, deleting an $n$-gon involves a complete understanding of SMTs on sets of $n$ fixed points. While the understanding is relatively uncomplicated and readily available for $n=3$, the same is not true for $n \geq 4$. Pollak [5] started the study of SMTs on four points and only recently [2] has a more thorough understanding of this topic been available, providing the basis for this paper.

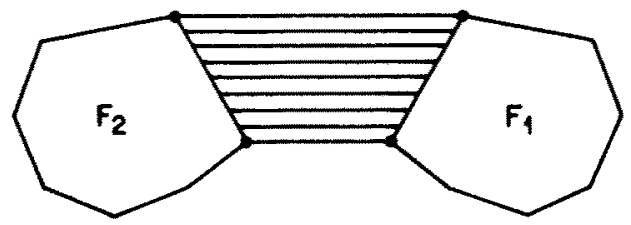

Fig. 2. The proposed decomposition. 


\section{Some Preliminary Results}

We first introduce some notation. The line segment between two points $X$ and $Y$ is denoted by $[X, Y], \Varangle X Y Z$ is the angle extending from $[X, Y]$ counterclockwise to $[Y, Z] .(X, Y)$ denotes the point $Z$ such that $X Y Z$ is an equilateral triangle and $\Varangle Y X Z=60^{\circ} . d[X, Y]$ denotes the distance between $X$ and $Y$. $P\left(X_{1}, \ldots, X_{m}\right)$ denotes the polygon whose vertices are $X_{1}, \ldots, X_{m}$ in order. $p\left(X_{1}, \ldots, X_{m}\right)$ denotes the path consisting of all sides of $P\left(X_{1}, \ldots, X_{m}\right)$ except the side $\left[X_{m}, X_{1}\right], p\left(X_{1}, \ldots, X_{m}\right)$ is called a Steiner path if $\measuredangle X_{i} X_{i+1} X_{i+2}=120^{\circ}$ for $i=1, \ldots, m-2 . F=P\left(X_{1}, \ldots, X_{m}\right)$ denotes that $F$ consists of the vertices of $P\left(X_{1}, \ldots, X_{m}\right)$.

A Steiner tree on $F$ is a tree interconnecting $F$ such that every pair of incident edges meet at an angle of at least $120^{\circ}$ and every Steiner point has three edges. A Steiner tree on $n$ fixed points is full if it contains $n-2$ Steiner points. Let $F=P(A, B, C, D)$. The $A B-C D$ tree denotes the full Steiner tree on $F$ such that $A$ and $B$ (hence $C$ and $D$ ) are adjacent to the same Steiner point. Similarly we can define the $A D-B C$ tree. Finally, $T_{i}, i \in\{A, B, C, D\}$, denotes a Steiner tree with a single Steiner point $s$ adjacent to all other fixed points except $i$ ( $i$ is adjacent to a fixed point). Whenever we use $T_{i}$ in this paper, it is always uniquely defined since the angle conditions on $P(A, B, C, D)$ allow only one fixed point to be adjacent to $i$.

The following three lemmas of [2] are crucially used in this paper:

Lemma 1. Suppose that $F=P(A, B, C, D)$ such that $\Varangle A \geq 120^{\circ}$ and $\Varangle B \geq 120^{\circ}$. Let the two diagonals $[A, C]$ and $[B, D]$ meet at $O$. If $\Varangle B O A>\Varangle A+\Varangle B-150^{\circ}$, then $p(D, A, B, C)$ is the SMT on $F$.

Corollary. $[C, D]$ is the longest side of $P(A, B, C, D)$.

Lemma 2. Suppose that $F=P(A, B, C, D)$ such that $\Varangle A+\Varangle B \geq 240^{\circ}, \Varangle A<120^{\circ}$, and $\Varangle B O A>\Varangle(D A) B C-30^{\circ}$. Then the SMT on $F$ is either $T_{A}$ or $T_{C}$. In particular, if $T$ is a tree with topology $A D-B C$, then length of $T>$ length of $T_{C}$.

Lemma 3. Suppose that $F=P(A, B, C, D)$ such that $\Varangle A \geq 120^{\circ}, \Varangle B \geq 120^{\circ}$, and $\Varangle B O A>\measuredangle A+\Varangle B-150^{\circ}$. Let $F^{\prime}=P\left(A^{\prime}, B^{\prime}, C^{\prime}, D^{\prime}\right)$ where $A^{\prime}, D^{\prime}$ are on $[A, D]$ and $B^{\prime}, C^{\prime}$ are on $[B, C]$ (see Fig. 3). Then the SMT on $F^{\prime}$ is not the $A^{\prime} B^{\prime}-C^{\prime} D^{\prime}$

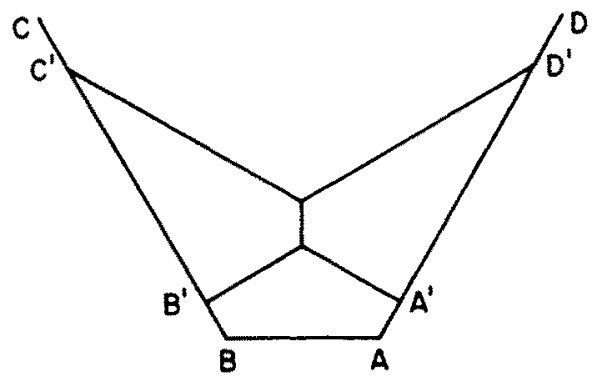

Fig. 3. SMT on $F^{\prime}$ is not the $A^{\prime} B^{\prime}-C^{\prime} D^{\prime}$ tree. 
tree. In particular, if $\Varangle D^{\prime} A^{\prime} B^{\prime}<120^{\circ}$, then $\Varangle B^{\prime} O^{\prime} A^{\prime}>\Varangle\left(D^{\prime} A^{\prime}\right) B^{\prime} C^{\prime}-30^{\circ}$ where $O^{\prime}$ is the intersection of $\left[A^{\prime}, C^{\prime}\right]$ and $\left[B^{\prime}, D^{\prime}\right]$.

We now state and prove some preliminary results.

Lemma 4. Let $A, B \in F$ and let $C, D$ be two arbitrary points in the SMT $T$ on $F$. Suppose that $[C, D]$ is the longest side of $P(A, B, C, D)$. Then no edge of $T$ can contain both $C$ and $D$.

Proof. Suppose to the contrary that there exists an edge in $T$ containing both $C$ and $D$. Let $p$ denote the path from $A$ to $D$ in $T$. If $p$ contains $C$, then we can substitute $[A, D]$ for $[C, D]$ to shorten the tree. Similarly, let $q$ denote the path from $B$ to $C$ in $T$. Then $q$ cannot contain $D$. Therefore $A$ is connected to $B$ through $p,[C, D]$, and $q$. But we can substitute $[A, B]$ for $[C, D]$ to shorten the tree, a contradiction to the assumption that $T$ is the SMT.

By using the fact that the internal angles of an $n$-gon sum to $(n-2) \cdot 180^{\circ}$, we easily obtain:

Lemma 5. Suppose that $P\left(Y_{1}, \ldots, Y_{m}\right)$ is contained in $P\left(X_{1}, \ldots, X_{n}\right)$ with $Y_{1}=$ $X_{1}$ and $Y_{m}=X_{n}$. Then

$$
\sum_{i=2}^{n-1} \Varangle X_{i}-\sum_{i=2}^{m-1} Y_{i} \leq(n-m) \cdot 180^{\circ}
$$

The inequality is strict if either $Y_{2} \neq X_{2}$ or $Y_{m-1} \neq X_{n-1}$.

Lemma 6. Suppose that $\Varangle A \geq 120^{\circ}, \Varangle B \geq 120^{\circ}$ in $P(A, B, C, D)$. Let $\Varangle s$ be an angle such that its two sides (or their extensions) meet $[B, C]$ at $C^{\prime}$ and $[A, D]$ at $D^{\prime}$, respectively (see Fig. 4). If $\Varangle D^{\prime} s C^{\prime} \leq 120^{\circ}$, then $\Varangle s D^{\prime} A+\Varangle A<180^{\circ}$, $\Varangle B C^{\prime} s+\Varangle B<180^{\circ}$.

Proof. Consider the pentagon $A B C^{\prime} s D^{\prime}$ :

$$
\begin{aligned}
& \Varangle s D^{\prime} A+\Varangle A<540^{\circ}-\not C^{\prime} s D^{\prime}-\Varangle B \leq 180^{\circ}, \\
& \Varangle B C^{\prime} s+\Varangle B<540^{\circ}-\not C^{\prime} s D^{\prime}-\Varangle A \leq 180^{\circ} .
\end{aligned}
$$

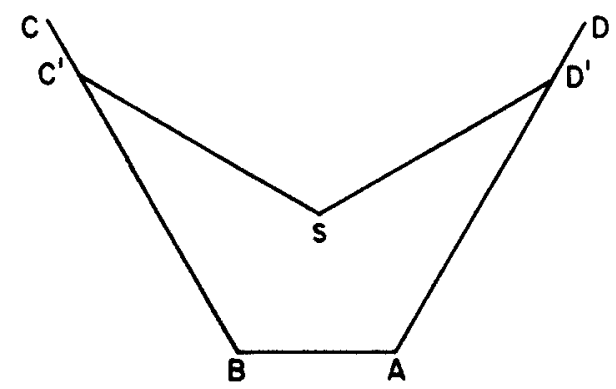

Fig. 4. A steiner path cuts $P(A, B, C, D)$. 


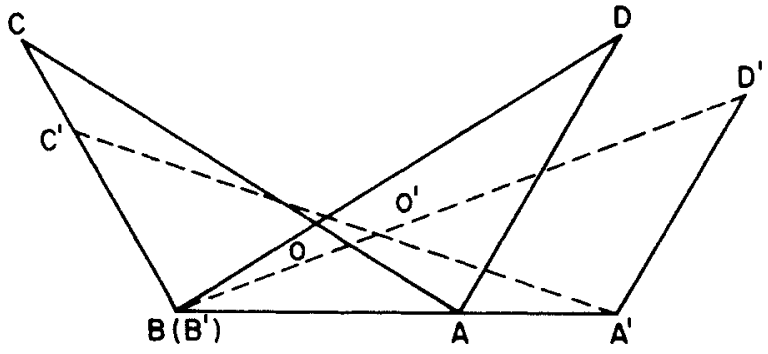

Fig. 5. $\Varangle B O A \leq \Varangle B^{\prime} O^{\prime} A^{\prime}$.

Corollary. $\Varangle s D^{\prime} A<60^{\circ}, \Varangle B C^{\prime} s<60^{\circ}$.

Lemma 7. Let $P(A, B, C, D)$ be such that $\Varangle A+\Varangle B \geq 180^{\circ}$. Without loss of generality, assume that $\Varangle A+\Varangle D \geq 180^{\circ}$. Then $\Varangle B \geq \Varangle C$ implies $d[C, D] \geq$ $d[A, B]$. Furthermore, $d[C, D]=d[A, B]$ only if $P(A, B, C, D)$ is a parallelogram.

Proof. Construct $[D, E]$ parallel to $[A, B]$ and meeting $[\mathrm{B}, \mathrm{C}]$ at $E$. Then

$$
\begin{aligned}
d[C, D] & \geq d[D, E] \quad \text { since } \quad \Varangle B \geq \Varangle C \\
\geq d[A, B] & \text { since } \quad \Varangle A+\Varangle B \geq 180^{\circ} .
\end{aligned}
$$

Lemma 8. Let $A B C D$ and $A^{\prime} B^{\prime} C^{\prime} D^{\prime}$ be two quadrilaterals such that $\Varangle A=\Varangle A^{\prime}$, $\Varangle B=\Varangle B^{\prime}, d[A, B] \leq d\left[A^{\prime}, B^{\prime}\right], d[A, D] \geq d\left[A^{\prime}, D^{\prime}\right]$, and $d[B, C] \geq d\left[B^{\prime}, C^{\prime}\right]$. Let $O\left(O^{\prime}\right)$ be the intersection of the two diagonals $[A, C]$ and $[B, D]\left(\left[A^{\prime}, C^{\prime}\right]\right.$ and $\left.\left[B^{\prime}, D^{\prime}\right]\right)$. Then $\Varangle B O A \leq \Varangle B^{\prime} O^{\prime} A^{\prime}$.

Proof. Superimpose $A^{\prime} B^{\prime} C^{\prime} D^{\prime}$ on $A B C D$ such that $B^{\prime}$ is on $B$ and the two sides of $\Varangle B^{\prime}$ overlaps the sides of $\measuredangle B$ (see Fig. 5).

Clearly, $\left[B^{\prime}, D^{\prime}\right]$ lies below $[B, D]$; hence $\Varangle A^{\prime} B^{\prime} D^{\prime} \leq \Varangle A B D$. Furthermore,

$$
\Varangle C A B=180^{\circ}-\Varangle A^{\prime} A C \geq \Varangle C^{\prime} A^{\prime} B^{\prime} .
$$

Therefore $\measuredangle B O A \leq \Varangle B^{\prime} O^{\prime} A^{\prime}$.

\section{The Main Results}

Theorem. Let $P(F)$ denote the Steiner polygon bounding the Steiner hull of the given set of points $F$. Let $A, B, C, D$ be four points on $P(F)$ satisfying;

(i) $P(A, B, C, D)$ is a convex quadrilateral,

(ii) $\measuredangle A \geq 120^{\circ}$ and $\measuredangle B \geq 120^{\circ}$,

(iii) Let the two diagonals $[A, C]$ and $[B, D]$ meet at $O$. Then

$$
\Varangle B O A \geq \Varangle A+\Varangle B-150^{\circ} \text {. }
$$




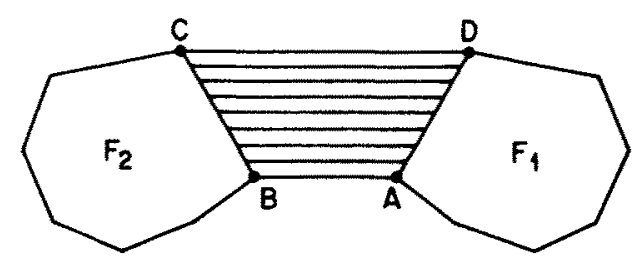

Fig. 6. The proposed decomposition.

Then no part of the SMT on $F$ can be inside of $P(A, B, C, D)$, i.e., the SMT on $F$ is the union of the SMT on $F_{1}$, the SMT on $F_{2}$ and the edge $[A, B]$ where $F_{1}$ $\left(F_{2}\right)$ is the set of fixed points lying inside the area bounded by $P(F)$ and $[A, D]$ ([B,C]) but disjoint to $P(A, B, C, D)$ (see Fig. 6).

Proof. Suppose to the contrary that the SMT $T$ on $F$ has a part $Q$ lying inside $P(A, B, C, D)$. Partition $Q$ into connected components $Q_{1}, Q_{2}, \ldots$ such that $Q_{i}$ and $Q_{j}$ are disconnected inside of $P(A, B, C, D)$. Let $Q^{\prime}$ denote the component closest to $[A, B]$. Since $T$ lies within $P(F), Q^{\prime}$ cannot terminate on an internal point of $[A, B]$. We show that $Q^{\prime}$ cannot exist.

Let $L$ denote the upper boundary of $Q^{\prime}$, i.e., $L$ is a Steiner path connecting a point $C^{\prime}$ on $[B, C]$ to a point $D^{\prime}$ on $[A, D]$. Suppose that $L$ has $m$ Steiner points between $C^{\prime}$ and $D^{\prime}$. Since the polygon consisting of $L$ and $\left[C^{\prime}, D^{\prime}\right]$ lies within $P\left(A, B, C^{\prime}, D^{\prime}\right)$, by Lemma 5

$$
\not A+\not B-m \cdot 120^{\circ}<(2-m) \cdot 180^{\circ} \text {. }
$$

Therefore $m=0$ or 1 . Suppose $m=0$, i.e., $L$ is the edge $\left[C^{\prime}, D^{\prime}\right]$. By the corollary of Lemma $1,\left[C^{\prime}, D^{\prime}\right]$ is the longest side of $P\left(A, B, C^{\prime}, D^{\prime}\right)$. By Lemma $4\left[C^{\prime}, D^{\prime}\right]$ is not part of the SMT, a contradiction to our assumption that $L \in T$.

Therefore we assume that $m=1$. Let $k$ be the number of Steiner points contained in $Q^{\prime}$. We consider several cases depending on the value of $k$. For convenience we will always assume that $[A, B]$ is horizontal.

(i) $k=1$ (see Fig. 7).

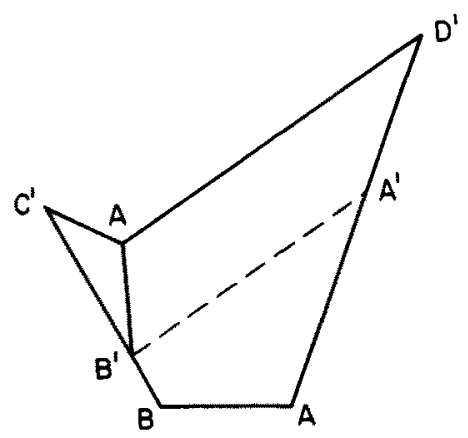

Fig. 7. The case $k=1$. 
Let $s$ be the Steiner point on $L$ and the third edge of $s$ meets $\left[B, C^{\prime}\right]$ at $B^{\prime}$. We first prove that

$$
d\left[s, D^{\prime}\right]>\max \left\{d\left[B, B^{\prime}\right], d[A, B]\right\} .
$$

Construct $\left[B^{\prime}, A^{\prime}\right]$ parallel to $\left[s, D^{\prime}\right]$ and meeting $\left[A, D^{\prime}\right]$ at $A^{\prime}$. By Lemma 6

$$
\measuredangle B^{\prime} s D^{\prime}+\Varangle s D^{\prime} A^{\prime} \leq 180^{\circ} \text {. }
$$

Hence by Lemma 7 and the corollary of Lemma 1,

$$
d\left[s, D^{\prime}\right] \geq d\left[B^{\prime}, A^{\prime}\right]>\max \left\{d\left[B, B^{\prime}\right], d[A, B]\right\} .
$$

Next we prove that

$$
d\left[s, B^{\prime}\right]+d\left[s, C^{\prime}\right]+d\left[s, D^{\prime}\right]>d\left[B^{\prime}, C^{\prime}\right]+d\left[A, D^{\prime}\right] .
$$

Construct equilateral triangles $B^{\prime} C^{\prime}\left(B^{\prime} C^{\prime}\right)$ and $B C^{\prime}\left(B C^{\prime}\right)$. Also construct $\left[\left(B C^{\prime}\right), E\right]$ parallel to $\left[s, D^{\prime}\right]$ and meeting $\left[A, D^{\prime}\right]$ at $E$, and construct $[E, G]$ parallel to $\left[\left(B C^{\prime}\right), C^{\prime}\right]$ and meeting $\left[s, D^{\prime}\right]$ or its extension at $G$. Finally, extend $\left[C^{\prime}, s\right]$ to meet $\left[\left(B C^{\prime}\right), E\right]$ at $s^{\prime}$. Consider triangles $B^{\prime} s\left(B^{\prime} C^{\prime}\right)$ and $B s^{\prime}\left(B C^{\prime}\right)$. Since the three lines $s^{\prime} s, B B^{\prime}$, and $\left(B C^{\prime}\right)\left(B^{\prime} C^{\prime}\right)$ pass through the same point $C^{\prime}$, by the theorem of Desargues, the intersections of the lines $s\left(B^{\prime} C^{\prime}\right)$ and $s^{\prime}\left(B C^{\prime}\right)$, $s B^{\prime}$ and $s^{\prime} b$, and $B^{\prime}\left(B^{\prime} C^{\prime}\right)$ and $B\left(B C^{\prime}\right)$ are collinear. But the first pair of lines are parallel, hence $\left[s, B^{\prime}\right]$ is parallel to $\left[s^{\prime}, B\right]$ (see Fig. 8 ).

We first prove that $d[s, G] \leq d\left[s, D^{\prime}\right]$, i.e., $G$ is on $\left[s, D^{\prime}\right]$. It suffices to prove that $\Varangle D^{\prime} E\left(B C^{\prime}\right) \geq \Varangle G E\left(B C^{\prime}\right)$, or

$$
\Varangle D^{\prime} E\left(B C^{\prime}\right)+\Varangle E\left(B C^{\prime}\right) C^{\prime} \geq \Varangle G E\left(B C^{\prime}\right)+\Varangle E\left(B C^{\prime}\right) C^{\prime}=180^{\circ} .
$$

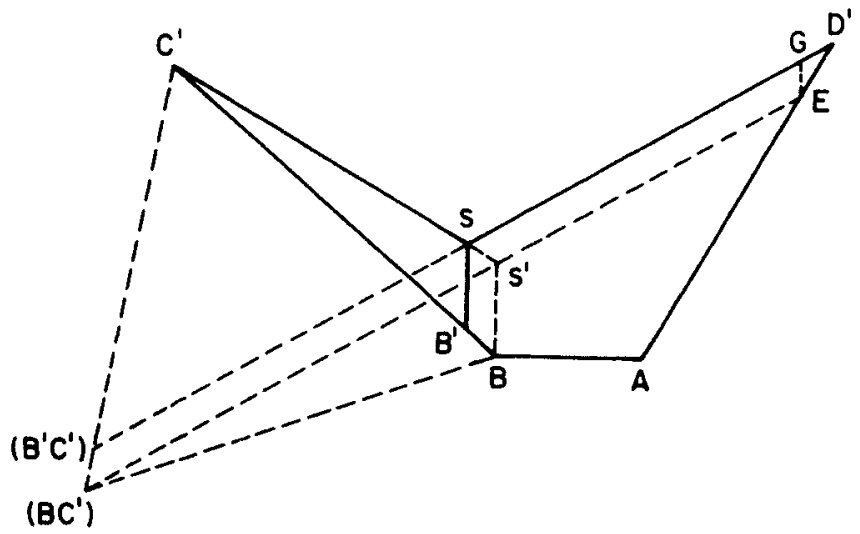

Fig. 8. $d\left[s, B^{\prime}\right]+d\left[s, C^{\prime}\right]+d\left[s, D^{\prime}\right]>d\left[B^{\prime}, C^{\prime}\right]+d\left[A, D^{\prime}\right]$. 
Since

$$
\measuredangle C^{\prime} s^{\prime} B+\not B\left(B C^{\prime}\right) C^{\prime}=120^{\circ}+60^{\circ}=180^{\circ},
$$

the four points $s^{\prime}, C^{\prime},\left(B C^{\prime}\right)$, and $B$ are cocircular. Thus

$$
\Varangle B\left(B C^{\prime}\right) s^{\prime}=\Varangle B C^{\prime} s^{\prime}
$$

Consequently,

$$
\begin{aligned}
\Varangle E\left(B C^{\prime}\right) C^{\prime}+\not D^{\prime} E\left(B C^{\prime}\right) & =60^{\circ}-\Varangle B C^{\prime} s^{\prime}+180^{\circ}-\Varangle s D^{\prime} A \\
& =240^{\circ}-\left(\Varangle B C^{\prime} s^{\prime}+\Varangle s D^{\prime} A\right) \\
& =240^{\circ}-\left(540^{\circ}-\not \Varangle C^{\prime} s D^{\prime}-\Varangle B-\Varangle A\right) \\
& =\Varangle A+\Varangle B-60^{\circ} \geq 180^{\circ} .
\end{aligned}
$$

Therefore,

$$
\begin{aligned}
d\left[s, B^{\prime}\right]+d\left[s, C^{\prime}\right]+d\left[s, D^{\prime}\right] & =d\left[\left(B^{\prime} C^{\prime}\right), D^{\prime}\right]=d\left[\left(B C^{\prime}\right), E\right]+d\left[G, D^{\prime}\right] \\
& =d\left[s^{\prime}, B\right]+d\left[s^{\prime}, C^{\prime}\right]+d\left[s^{\prime}, E\right]+d\left[G, D^{\prime}\right]
\end{aligned}
$$

By Lemma $1, p\left(E, A, B, C^{\prime}\right)$ is the SMT for $P\left(A, B, C^{\prime}, E\right)$. Since the tree consisting of the four edges $\left[s^{\prime}, B\right],\left[s^{\prime}, C^{\prime}\right],\left[s^{\prime}, E\right]$, and $[A, B]$ is a Steiner tree on $P\left(A, B, C^{\prime}, E\right)$, it is longer than $p\left(A, B, C^{\prime}, E\right)$. Hence

$$
d\left[s^{\prime}, B\right]+d\left[s^{\prime}, C^{\prime}\right]+d\left[s^{\prime}, E\right]>d\left[C^{\prime}, B\right]+d[A, E]
$$

Furthermore, it is easily verified that

$$
d\left[B, B^{\prime}\right]=d\left[\left(B C^{\prime}\right),\left(B^{\prime} C^{\prime}\right)\right]=d[E, G]
$$

Hence

$$
\begin{aligned}
d\left[s, B^{\prime}\right]+d\left[s, C^{\prime}\right]+d\left[s, D^{\prime}\right] & >d\left[C^{\prime}, B\right]+d[A, E]+d\left[G, D^{\prime}\right] \\
& =d\left[C^{\prime}, B^{\prime}\right]+d[E, G]+d[A, E]+d\left[G, D^{\prime}\right] \\
& >d\left[C^{\prime}, B^{\prime}\right]+d[A, E]+d\left[E, D^{\prime}\right] \\
& =d\left[C^{\prime}, B^{\prime}\right]+d\left[A, D^{\prime}\right]
\end{aligned}
$$


We now show that if we replace the three edges $\left[s, B^{\prime}\right],\left[s, C^{\prime}\right]$, and $\left[s, D^{\prime}\right]$ by the two edges $\left[B^{\prime}, C^{\prime}\right]$ and $\left[A, D^{\prime}\right]$, which are shorter, we still have a tree interconnecting $F$. It suffices to prove that $D^{\prime}$ is still connected to $B^{\prime}$ (hence to $C^{\prime}$ ). Consider the path from $A$ to $s$ in $T$. This path cannot go through $D^{\prime}$ for otherwise we can replace $\left[s, D^{\prime}\right]$ by either $\left[B, B^{\prime}\right]$ or $[A, B]$ to shorten the tree, a contradiction to the assumption that $T$ is the SMT. Therefore the path must go through either $B^{\prime}$ or $C^{\prime}$, say $C^{\prime}$. Hence $D^{\prime}$ is connected to $B^{\prime}$ in the new tree through $\left[D^{\prime}, A\right]$, to the path from $A$ to $C^{\prime}$, and $\left[C^{\prime}, B\right]$.

(ii) $k=2$. By Lemma 3 this case cannot exist.

For $k \geq 3$, let $s_{1}$ denote the Steiner point on $L$ and let $s_{1}$ be adjacent to a Steiner point $s_{2}$. Without loss of generality, we may assume that $s_{2}$ is adjacent to a Steiner point $s_{3}$ such that $\Varangle s_{3} s_{2} s_{1}=120^{\circ}$.

(iii) $k=3$. Let the third edge of $s_{2}$ meet $\left[\mathrm{B}, \mathrm{C}^{\prime}\right]$ at $B^{\prime}$. Let the edge of $s_{3}$ parallel to $\left[s_{1}, D^{\prime}\right]$ meet $\left[A, D^{\prime}\right]$ at $E$ and let the third edge of $s_{3}$ meet either $\left[A, D^{\prime}\right]$ or $\left[B, B^{\prime}\right]$ at $G$. We consider four subcases:

Subcase 1. $B^{\prime}$ is not higher than $G$ (see Fig. 9). Then $G$ must be on $\left[A, D^{\prime}\right]$.

Let $\bar{Q}$ be obtained from $Q^{\prime}$ by substituting $\left[s_{2}, G\right]$ for the three edges of $s_{3}$. Then $\bar{Q}$ interconnects $P\left(G, B^{\prime}, C^{\prime}, D^{\prime}\right)$. now clearly $\Varangle D^{\prime} G B^{\prime} \geq 120^{\circ}$. If $\Varangle G B^{\prime} C^{\prime} \geq$ $120^{\circ}$, then by Lemma $1, p\left(D^{\prime}, G, B^{\prime}, C^{\prime}\right)$ is the SMT on $P\left(G, B^{\prime}, C^{\prime}, D^{\prime}\right)$. If ${ }_{4} G B^{\prime} C^{\prime}<120^{\circ}$, then by Lemmas 2 and $3, T_{D^{\prime}}$ (with respect to $P\left(G, B^{\prime}, C^{\prime}, D^{\prime}\right)$ ) is shorter than $\bar{Q}$. By angle consideration it is easily verified that $D^{\prime}$ is adjacent to $G$ in $T_{D^{\prime}}$. Since $\bar{Q}$ is clearly shorter than $Q^{\prime}$, in any case we can replace $Q^{\prime}$ by a shorter tree which also interconnects the five points $B^{\prime}, C^{\prime}, D^{\prime}, E$, and $G$, a contradiction to the assumption $Q^{\prime} \in T$.

Subcase 2. $B^{\prime}$ is higher than $G$ but not higher than $s_{3}$ (see Fig. 10).

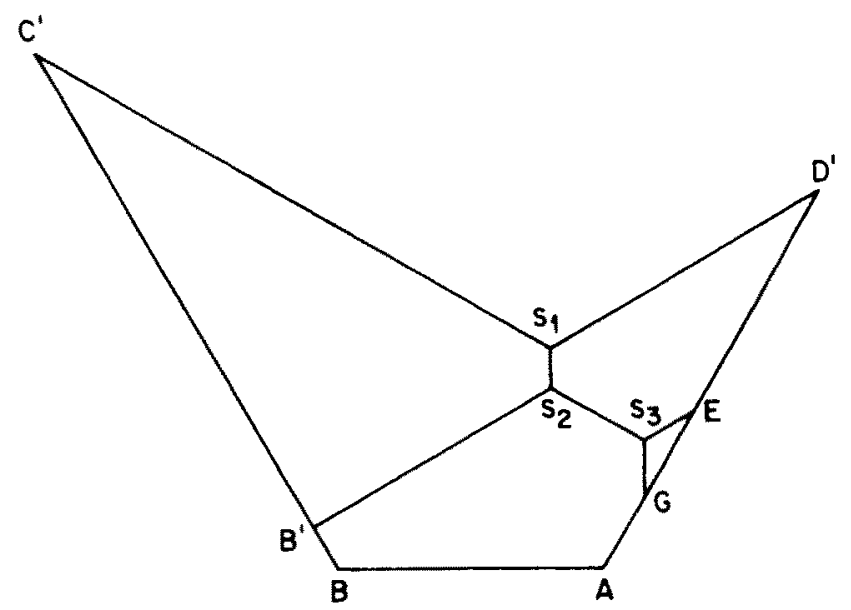

Fig. 9. $B^{\prime}$ Not higher than $G$. 


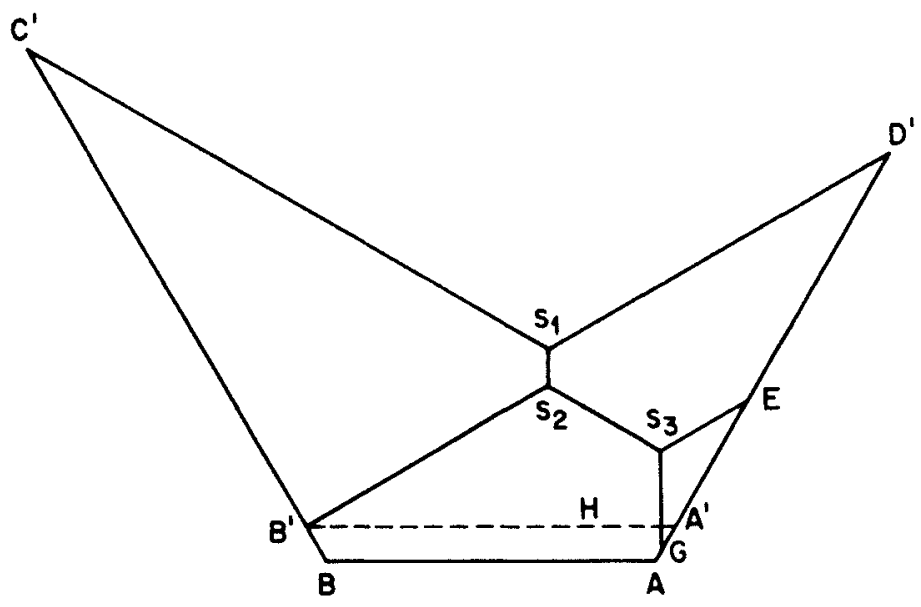

Fig. 10. $B^{\prime}$ Higher than $G$ but not higher than $s_{3}$.

Construct $\left[B^{\prime}, A^{\prime}\right]$ parallel to $[A, B]$ and meeting $\left[s_{3}, G\right],\left[A, D^{\prime}\right]$ at $H$ and $A^{\prime}$, respectively. Let $\bar{Q}^{\prime}$ be the part of $Q^{\prime}$ above $\left[A^{\prime}, B^{\prime}\right]$. Let $\bar{Q}$ be obtained from $\bar{Q}^{\prime}$ by substituting $\left[H, A^{\prime}\right]$ for $\left[s_{3}, E\right]$. By Lemma 6 and its corollary, $\measuredangle s_{3} E A^{\prime}+$ $\Varangle E A^{\prime} H=\measuredangle s_{1} D^{\prime} A+\Varangle A<180^{\circ}, \Varangle s_{3} E A^{\prime}+\Varangle H s_{3} E<60^{\circ}+120^{\circ}=180^{\circ} . \quad$ Furthermore, $\Varangle E A^{\prime} H=\Varangle A \geq 120^{\circ}>\Varangle s_{3} E A^{\prime}$. By Lemma $7, d\left[H, A^{\prime}\right]<d\left[s_{3}, E\right]$. Hence $\bar{Q}$ is shorter than $\bar{Q}^{\prime}$. But $\bar{Q}$ is a tree connecting $A^{\prime}, B^{\prime}, C^{\prime}, D^{\prime}$, hence longer than $p\left(D^{\prime}, A^{\prime}, B^{\prime}, C^{\prime}\right)$ which is the SMT on $P\left(A^{\prime}, B^{\prime}, C^{\prime}, D^{\prime}\right)$ by Lemma 1 . It follows $p\left(A^{\prime}, B^{\prime}, C^{\prime}, D^{\prime}\right)$ is shorter than $\bar{Q}^{\prime}$ but also interconnects the five points $B^{\prime}, C^{\prime}, D^{\prime}, E$, and $H$, a contradiction to the assumption that $\bar{Q}^{\prime} \in T$.

Subcase 3. $B^{\prime}$ is higher than $s_{3}$ and $G$ is on $\left[A, D^{\prime}\right]$ (see Fig. 11).

Construct $\left[s_{3}, I\right]$ parallel to $[A, B]$ and meeting $\left[B, B^{\prime}\right]$ at $I$. Construct $\left[s_{3}, H\right]$

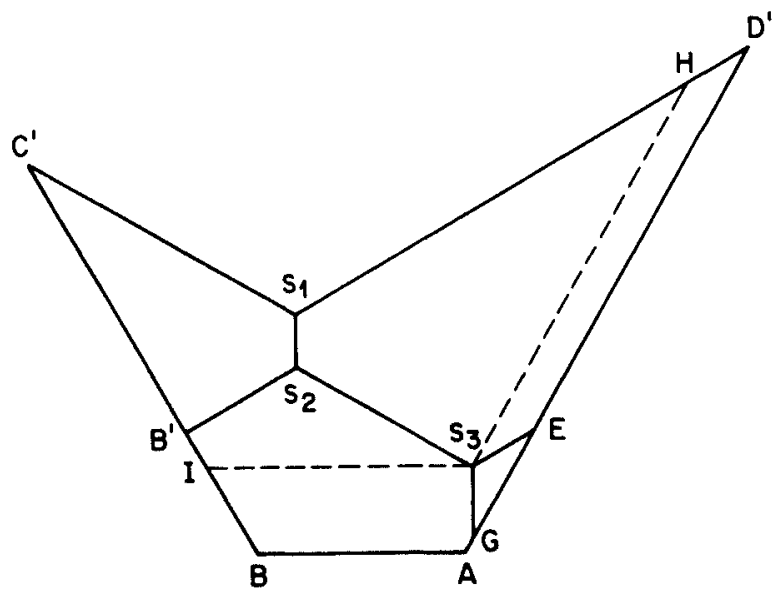

Fig. 11. $B^{\prime}$ Higher than $s_{3}$ and $G$ on $\left[A, D^{\prime}\right]$. 
parallel to $\left[A, D^{\prime}\right]$ and meeting $\left[s_{1}, D^{\prime}\right]$ at $H$. In the trapezoid $A B I s_{3}$

$$
\begin{aligned}
\not s_{3} A B+\Varangle A B I & =\Varangle A+\not B-\not \measuredangle G A s_{3} \\
& \geq 240^{\circ}-\not \measuredangle E G s_{3}>180^{\circ}
\end{aligned}
$$

by Lemma 6 . Therefore $d\left[s_{3}, I\right]>d[A, B]$. Furthermore,

$$
d\left[s_{3}, H\right]=d\left[E, D^{\prime}\right]<d[A, D]
$$

and

$$
d\left[I, C^{\prime}\right]<d[B, C]
$$

Let $O^{\prime}$ be the intersection of $\left[s_{3}, C^{\prime}\right]$ and $[I, H]$. By Lemma $8, \Varangle I O^{\prime} s_{3} \geq \Varangle B O A \geq$ $\Varangle A+\Varangle B-150^{\circ}=\Varangle H s_{3} I+\Varangle s_{3} I C^{\prime}-150^{\circ}$. By Lemma 3, the SMT on $P\left(s_{3}, B^{\prime}, C^{\prime}, H\right)$ is not the $s_{3} B^{\prime}-C^{\prime} H$ tree, a contradiction to the assumption $Q^{\prime} \in T$.

Subcase 4. $b^{\prime}$ is higher than $s_{3}$ and $G$ is on $\left[B, B^{\prime}\right]$ (see Fig. 12).

Construct $\left[G, A^{\prime}\right]$ parallel to $[B, A]$ and meeting $\left[A, D^{\prime}\right]$ at $A^{\prime}$. Let $\bar{Q}$ be obtained from $Q^{\prime}$ by substituting $\left[G, A^{\prime}\right]$ for $\left[s_{3}, E\right]$. We show that $\bar{Q}$ is shorter than $Q^{\prime}$. Consider $P\left(A^{\prime}, G, C^{\prime}, D^{\prime}\right)$. By Lemma 6,

$$
\Varangle s_{3} E A^{\prime}+\Varangle E A^{\prime} G=\Varangle s_{1} D^{\prime} E+\Varangle A<180^{\circ} .
$$

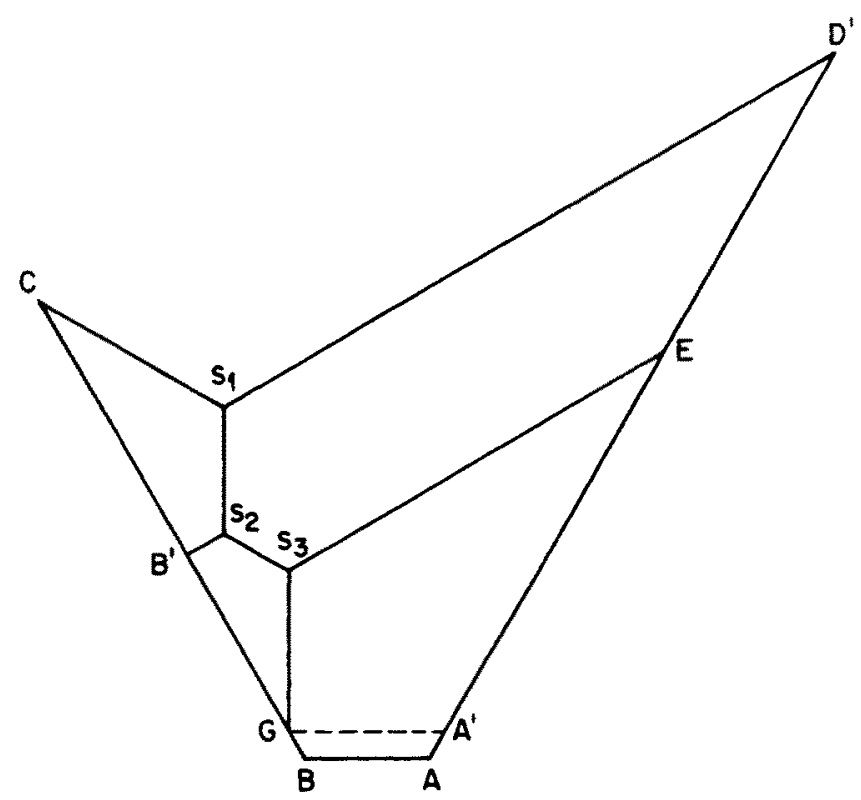

Fig. 12. $B^{\prime}$ Higher than $s_{3}$ and $G$ on $\left[B, B^{\prime}\right]$. 
Furthermore,

$$
\begin{aligned}
\Varangle s_{3} G B^{\prime} & =120^{\circ}-{ }_{4} G B^{\prime} s_{2}=\Varangle s_{2} B^{\prime} C^{\prime}-60^{\circ} \\
& =120^{\circ}-\Varangle B^{\prime} C^{\prime} s_{1}-60^{\circ}<60^{\circ} .
\end{aligned}
$$

Hence

$$
\not E A^{\prime} G+\not A^{\prime} G s_{3}=\Varangle A+\not B-\not s_{3} G B^{\prime}>180^{\circ} \text {. }
$$

Finally we have

$$
\Varangle E A^{\prime} G=\Varangle A>\Varangle s_{3} E A .
$$

By Lemma $7, d\left[s_{3}, E\right]>d\left[G, A^{\prime}\right]$. Hence $\bar{Q}$ is shorter than $Q^{\prime}$.

Let $O^{\prime}$ be the intersection of $\left[A^{\prime}, C^{\prime}\right]$ and $\left[G, D^{\prime}\right]$. By Lemma 8 ,

$$
\Varangle G O^{\prime} A^{\prime}>\measuredangle B O A \geq \Varangle A+\Varangle B-150^{\circ}=\Varangle D^{\prime} A^{\prime} G+\Varangle A^{\prime} G C^{\prime}-150^{\circ} \text {. }
$$

By Lemma $1, p\left(D^{\prime}, A^{\prime}, G, C^{\prime}\right)$ is the SMT of $P\left(D^{\prime}, A^{\prime}, G, C^{\prime}\right)$. In particular, $p\left(D^{\prime}, A^{\prime}, G, C^{\prime}\right)$ is shorter than $\bar{Q}$, hence shorter than $Q^{\prime}$. But $p\left(D^{\prime}, A^{\prime}, G, C^{\prime}\right)$ also interconnects the five points $D^{\prime}, E, G, B^{\prime}$, and $C^{\prime}$, a contradiction to the fact that $Q^{\prime} \in T$.

(iv) $k \geq 4$. Let $e$ be the edge at $s_{3}$ parallel to $\left[s_{1}, D^{\prime}\right]$. Then $e$ must meet $\left[A, D^{\prime}\right]$, say at $E$, for $e$ cannot contain a Steiner point $s^{\prime}$ before it reaches $E$. The reason is that the Steiner path starting from $s_{3}$ toward $s^{\prime}$ and always turning counterclockwise will run into the Steiner path $p\left(D^{\prime}, s_{1}, s_{2}\right)$. Therefore either $s_{2}$ is adjacent to three Steiner points or $s_{2}$ and $s_{3}$ are both adjacent to two Steiner points. In the latter case let $s_{3}$ be adjacent to $s_{2}$ and $s_{4}$ and let the third edge of $s_{2}$ meet $\left[B, C^{\prime}\right]$ at $I$. Let the two other edges of $s_{4}$ (or their extensions) meet $\left[A, D^{\prime}\right]$ and $\left[B, C^{\prime}\right]$ at $A^{\prime}$ and $B^{\prime}$, respectively. We also let $L_{4}\left(R_{4}\right)$ denote the Steiner path starting from the left (right) edge of $s_{4}$, always turning clockwise (counterclockwise) and ending at a point $B^{\prime \prime}\left(A^{\prime \prime}\right)$ on $\left[B^{\prime}, C^{\prime}\right]\left(\left[A^{\prime}, D^{\prime}\right]\right)$.

Subcase 1. $s_{2}$ and $s_{3}$ are both adjacent to two Steiner points and $B^{\prime}$ is not higher than $A^{\prime}$ (see Fig. 13).

At $B^{\prime}$ construct a line parallel to $\left[s_{1}, s_{2}\right]$. Since, by Lemma $6, \Varangle I C^{\prime} s_{1}+\not \Varangle C^{\prime} s_{1} s_{2}<$ $180^{\circ}$, this line must meet either $\left[I, s_{2}\right]$ or $\left[s_{2}, s_{3}\right]$ at, say, $G$. Let $J$ denote either $G$ or $s_{2}$ depending on which point is to the right of the other. Construct $\left[B^{\prime}, H\right]$ parallel to $[A, B]$ and meeting $\left[A, D^{\prime}\right]$ at $H$. Let $\bar{Q}^{\prime}$ be the part of $Q^{\prime}$ above $\left[B^{\prime}, H\right]$. Let $\bar{Q}$ be obtained from $\bar{Q}^{\prime}$ by substituting $\left[B^{\prime}, G\right]$ and $\left[B^{\prime}, H\right]$ for $\left[J, s_{3}\right]$, $\left[s_{3}, s_{4}\right], L_{4}$, and $R_{4}$. It is easily verified that

$$
d\left(B^{\prime}, G\right)=d\left[J, s_{3}\right]+d\left[s_{3}, s_{4}\right]
$$

and

$$
d\left[B^{\prime}, H\right] \leq D\left[B^{\prime \prime}, A^{\prime \prime}\right]<\text { length of } L_{4}+\text { length of } R_{4}
$$




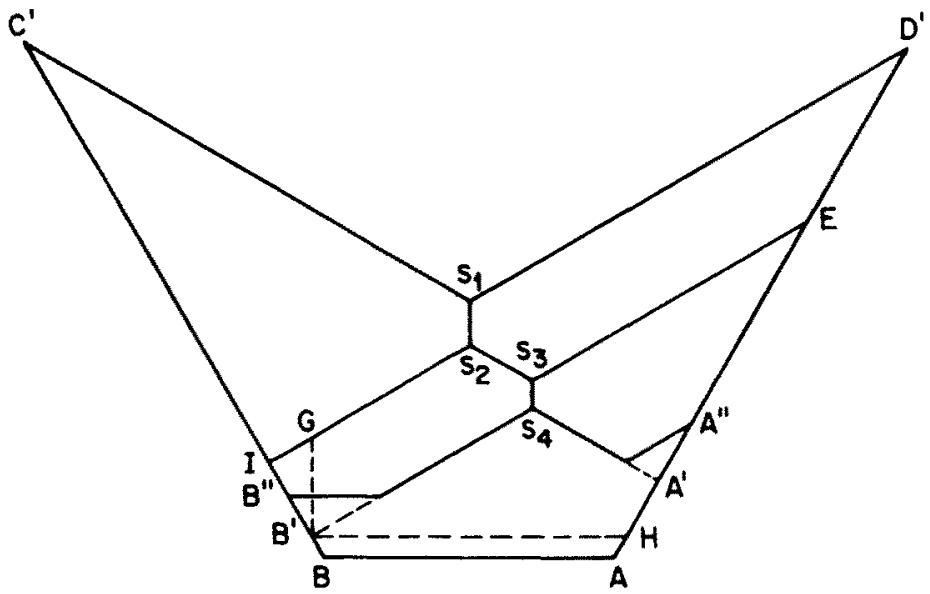

Fig. 13. $B^{\prime}$ Not higher than $A^{\prime}$.

Therefore $\bar{Q}$ is shorter than $\bar{Q}^{\prime}$. But $\bar{Q}$ is a tree interconnecting $\left\{H, B^{\prime}, C^{\prime}, D^{\prime}\right\}$. By Lemmas 1 and $8, p\left(H, B^{\prime}, C^{\prime}, D^{\prime}\right)$ is shorter than $\bar{Q}$, hence shorter than $\bar{Q}^{\prime}$, a contradiction to the assumption that $\bar{Q}^{\prime} \in T$.

Subcase $2 . s_{2}$ and $s_{3}$ are both adjacent to two Steiner points and $A^{\prime}$ is not higher than $B^{\prime}$ (see Fig. 14).

Construct $\left[A^{\prime}, H\right]$ parallel to $[A, B]$ and meeting $\left[B, C^{\prime}\right]$ at $H$. Let $\bar{Q}^{\prime}$ be the part of $Q^{\prime}$ above $\left[A^{\prime}, H\right]$. Let $\bar{Q}$ be obtained from $\bar{Q}^{\prime}$ by substituting $\left[s_{4}, A^{\prime}\right]$ and $\left[\mathrm{A}^{\prime}, H\right]$ for $\left[s_{3}, E\right], L_{4}$, and $R_{4}$. By Lemma $6, \measuredangle s_{3} E A^{\prime}<60^{\circ}$. Hence $\measuredangle E A^{\prime} s_{4}>60^{\circ}>$ $\Varangle s_{3} E A^{\prime}$. Furthermore, $\Varangle s_{4} s_{3} E+\Varangle A^{\prime} s_{4} s_{3}=240^{\circ}>180^{\circ}$. By Lemma $7, d\left[s_{3}, E\right]>$ $d\left[s_{4}, A^{\prime}\right]$. It is also easily verified that length of $L_{4}+$ length of $R_{4}>d\left[A^{\prime}, H\right]$.

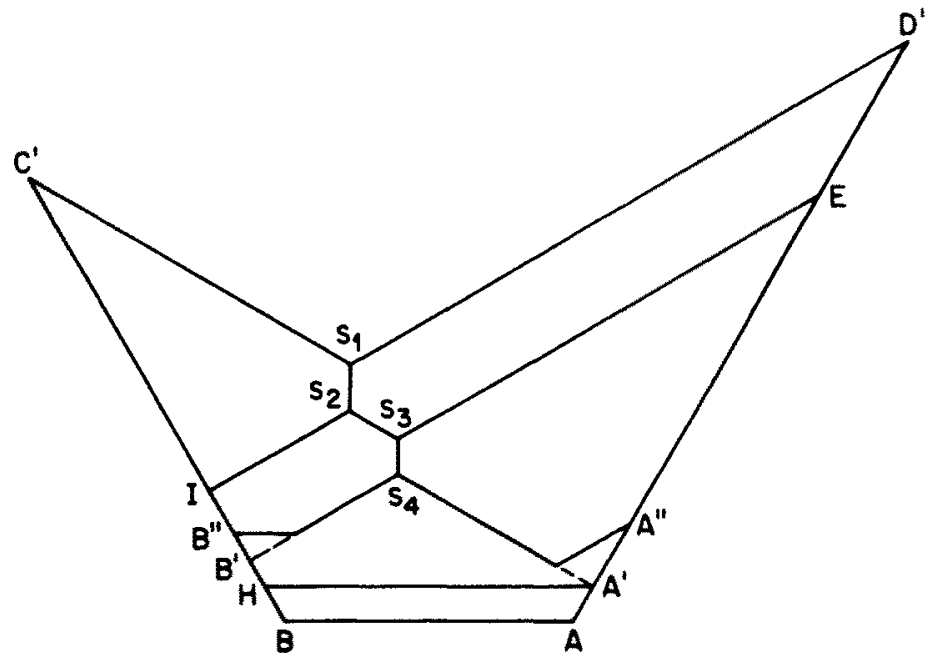

Fig. 14. $A^{\prime}$ Not higher than $B^{\prime}$. 
Hence $\bar{Q}$ is shorter than $\bar{Q}^{\prime}$. But $\bar{Q}$ is a tree interconnecting $\left\{A^{\prime}, B^{\prime}, C^{\prime}, D^{\prime}\right\}$. By Lemmas 1 and $8, p\left(A^{\prime}, H, C^{\prime}, D^{\prime}\right)$ is shorter than $\bar{Q}$, hence shorter than $\bar{Q}^{\prime}$, a contradiction to the assumption $\bar{Q}^{\prime} \in T$.

Subcase 3. $s_{2}$ is adjacent to three Steiner points. We first make the observation that the proofs for subcases 1 and 2 are still valid if there exists a Steiner point $s_{5}$ on $\left[s_{2}, I\right]$. It is obvious for subcase 2 since $\left[s_{2}, I\right]$ is not used in the proof at all. For subcase 1 note that $s_{5}$ cannot be to the right of $G$ otherwise the Steiner path starting from $\left[s_{2}^{\prime}, s_{5}\right]$ and always turning counterclockwise will run into $L_{4}$. Therefore the inequality

$$
d\left[s_{2}, G\right] \leq d\left[s_{2}, s_{5}\right]
$$

substitutes for the inequality

$$
d\left[s_{2}, G\right] \leq d\left[s_{2}, I\right]
$$

in the proof of subcase 1 and nothing else need be changed.

Therefore we may assume that neither of the two Steiner points $s_{3}$ and $s_{4}$ adjacent to $s_{2}$ is adjacent to another Steiner point. In other words, $Q^{\prime}$ contains exactly four Steiner points.

Let $e_{1}\left(e_{2}\right)$ denote the edge at $s_{3}\left(s_{4}\right)$ parallel to $\left[s_{1}, s_{2}\right]$. Then $e_{1}\left(e_{2}\right)$ meets either $\left[A, D^{\prime}\right]$ or $\left[B, C^{\prime}\right]$. Suppose that $e_{1}$ and $e_{2}$ meet the same side, say $\left[B, C^{\prime}\right]$. The proof is exactly the same as for subcase 4 of the case $k=3$ since the left branch of $s_{2}$ is kept intact in that proof. Therefore it suffices to consider the case that $e_{1}$ meets $\left[A, D^{\prime}\right]$ and $e_{2}$ meets $\left[B, C^{\prime}\right]$. Without loss of generality, assume that $s_{3}$ is not higher than $s_{4}$. Construct $\left[s_{3}, G\right]$ parallel to $[A, B]$ and meeting $\left[B, C^{\prime}\right]$ at $G$ We first consider the case that $e_{2}$ stays above $\left[s_{3}, G\right]$ (see Fig. 15).

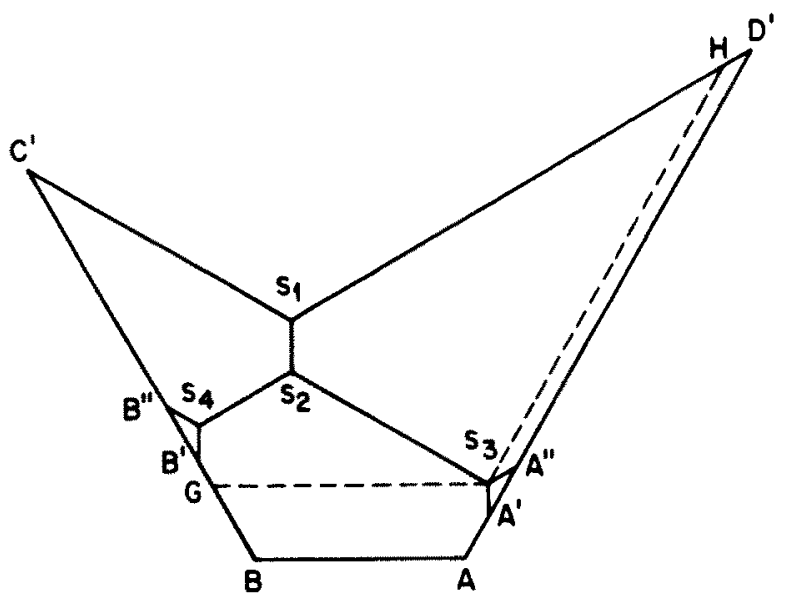

Fig. 15. $e_{2}$ above $\left[s_{3}, G\right]$. 


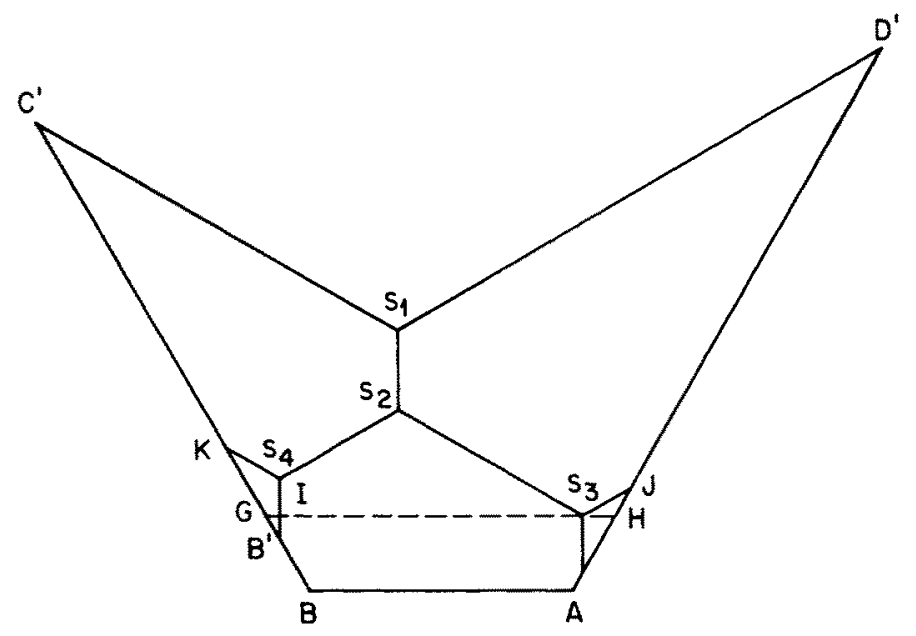

Fig. 16. $G$ not below $B^{\prime}$.

Construct $\left[s_{3}, H\right]$ parallel to $[A, D]$ and meeting $\left[s_{1}, D^{\prime}\right]$ at $H$. Let $\bar{Q}^{\prime}$ be the part of $Q^{\prime}$ lying within $P\left(s_{3}, G, C^{\prime}, H\right)$. Let the two edges of $s_{3}\left(s_{4}\right)$ meet $\left[A, D^{\prime}\right]$ $\left(\left[B, C^{\prime}\right]\right)$ at $A^{\prime}$ and $A^{\prime \prime}\left(B^{\prime}\right.$ and $\left.B^{\prime \prime}\right)$ such that $\left[s_{3}, A^{\prime}\right]\left(\left[s_{2}, B^{\prime}\right]\right)$ is parallel to $\left[s_{1}, s_{2}\right]$. In the trapezoid $A B G s_{3}$

$$
\begin{aligned}
\not s_{3} A B+\not \Varangle A B G & =\Varangle A+\not \measuredangle B-\not A^{\prime} A s_{3} \\
& >240^{\circ}-\not \measuredangle A^{\prime \prime} A^{\prime} s_{3} \geq 180^{\circ} \quad \text { By Lemma } 6 .
\end{aligned}
$$

Hence $d\left[s_{3}, G\right] \geq d[A, B]$. It is also clear that $d\left[G, C^{\prime}\right] \leq d\left[B, C^{\prime}\right]$ and

$$
d\left[s_{3}, H\right]=d\left[A^{\prime \prime}, D^{\prime}\right]<d\left[A, D^{\prime}\right] .
$$

Let $O^{\prime}$ denote theintersection of $\left[s_{3}, C^{\prime}\right]$ and $[\mathrm{G}, \mathrm{H}]$. By Lemma 8 ,

$$
{ }_{4} G O^{\prime} s_{3} \leq \Varangle B O A \leq \Varangle A+\Varangle B-150^{\circ}=\Varangle H S_{3} G+\Varangle s_{3} G C^{\prime}-150^{\circ} \text {. }
$$

Since $P\left(s_{3} G C^{\prime} H\right)$ contains only three Steiner points, it was proved in subcase (iii) that $T$ cannot contain $\bar{Q}^{\prime}$.

Next we consider the case that $e_{2}$ meets $\left[s_{3}, G\right]$ at $I$ (see Fig. 16).

Extend $\left[s_{3}, G\right]$ to meet $\left[A, D^{\prime}\right]$ at $H$. Let the third edge at $s_{3}\left(s_{4}\right)$ meet $\left[A, D^{\prime}\right]$ $\left(\left[B, C^{\prime}\right]\right)$ at $J(K)$. Let $\bar{Q}^{\prime}$ be the part of $Q^{\prime}$ above $[H, G]$. Clearly, $d\left[s_{3}, H\right]<$ $d\left[s_{3}, J\right]$ and, by Lemma 6 , its corollary, and Lemma $7, d[1, G]<d\left[s_{4}, K\right]$. Let $\bar{Q}$ be the tree obtained from $\bar{Q}^{\prime}$ by substituting $\left[s_{3}, H\right]$ and $[I, G]$ for $\left[s_{3}, J\right]$ and $\left[s_{4}, K\right]$. Then $\bar{Q}$ is shorter than $\bar{Q}^{\prime}$. Furthermore, by Lemmas 1 and 8 , $p\left(D^{\prime}, H, G, C^{\prime}\right)$ is shorter than $\bar{Q}$, hence shorter than $\bar{Q}^{\prime}$, a contradiction to the fact $\bar{Q}^{\prime} \in T$.

\section{References}

1. E. J. Cockayne, On the efficiency of the algorithm for Steiner minimal trees, SIAM J. Appl. Math. $18(1970)$, 150-159. 
2. D. Z. Du, F. K. Hwang, and G. Y. Ting, Steiner minimal trees on sets of four points, Discrete Comput. Geom. to appear.

3. M. R. Garey, R. L. Graham, and D. S. Johnson, The complexity of computing Steiner minimal trees, SIAM J. Appl. Math. 32 (1977), 835-859.

4. E. N. Gilbert and H. O. Pollak, Steiner minimal trees, SIAM J. Appl. Math. 16 (1968), 1-29.

5. H. O. Pollak, Some remarks on the Steiner problem, J. Combin. Theory Ser. A 24 (1978), 279-295.

Received March 24, 1986, and in revised form October 20, 1986. 